\title{
HISTAMINE METABOLISM IN DISEASES OF THE LIVER
}

\section{By ROSS G. MITCHELL, 1 HUGH R. BUTT, AND CHARLES F. CODE}

\author{
(From the Section of Medicine and Section of Physiology, Mayo Clinic and Mayo Foundation, 2 \\ Rochester, Minn.)
}

(Submitted for publication February 8, 1954 ; accepted May 14, 1954)

Recent experimental studies in animals indicate that the liver plays a part in the inactivation of histamine in the body, by removing this substance from the blood (1) and by acetylating it to form acetyl or conjugated histamine (2-5). The supposition, therefore, that disorders of hepatic function in man may alter the metabolism of histamine seems reasonable. Some clinical evidence of this is provided by the studies of Chambon and Berthier (6) who found that marked hepatic insufficiency or cirrhosis was often accompanied by high levels of histamine in the blood.

A disturbance of histamine metabolism has been held responsible for the pruritus which sometimes occurs in obstructive jaundice (7). Bile salts have been shown to release histamine from the skin (8) and from the liver (1), and Anrep and Barsoum (9) reported that ligature of the common bile duct in dogs caused a rise in blood histamine which they attributed to release of histamine by retained bile.

Our study was undertaken to determine whether an abnormal metabolism of histamine could be detected in patients with disordered hepatic function by examination of the blood and urine, and whether in patients with obstructive jaundice any changes which might be found could be related to the degree of itching.

\section{METHODS AND MATERIAL}

Histamine was estimated in blood by a modification (10) of the method of Barsoum and Gaddum (11). After the trichloracetic acid filtrate had been boiled with hydrochloric acid and dried twice in the presence of alcohol, the dry material was extracted three times, using 10,5 , and $5 \mathrm{ml}$. aliquots of absolute alcohol, in order to remove potassium (12). The alcohol-insoluble material was separated by centrifugation, and the alcoholic extract then taken to dryness. The dried residue was

\footnotetext{
1 Rockefeller Foundation Fellow in Physiology.

2 The Mayo Foundation is a part of the Graduate School of the University of Minnesota.
}

dissolved in diluted Tyrode's solution, neutralized and then used in the final assay of histamine on a segment of guinea-pig ileum.

Blood was drawn between 8 and 9 a.m. with syringes moistened with a solution of heparin in saline solution. Samples of the blood in the syringe were taken for determination of histamine and enumeration of epsinophils. The eosinophils were counted accorfing to the method of Randolph (13). The amount of bilirubin in the serum was determined according to the method published by Powell (14).

Free and conjugated histamine in the urine were measured by the method of Roberts and Adam (15). The mean recovery of free histamine by this procedure is 67 per cent $(15,16)$; no correction has been made for the loss in the computation of results in this paper.

Urine was collected in chemically clean bottles of 2-liter capacity, containing $10 \mathrm{ml}$. of twice normal hydrochloric acid to maintain the urine at $\mathrm{pH} 5$ or less. Extraction was always started within 24 hours of completing the collection and in the interval the urine was stored in a refrigerator. Tests have shown that no loss of histamine occurs under these conditions.

All values for both blood and urinary histamine reported in this paper are the means of duplicate samples, expressed in terms of the free base. Duplicate determinations were made of the histamine content of 24 different samples of urine and 26 different samples of blood. The duplicate estimates of the free histamine in urine never differed by more than 10 per cent. The differences between duplicate determinations of the conjugated histamine in urine exceeded 10 per cent only twice while the difference between duplicate estimates of the blood histamine was more than 10 per cent on four occasions. In all of the tests, however, there was only one instance in which the difference between duplicates exceeded 20 per cent.

Single determinations of histamine in the blood and urine were made in seven patients with cirrhosis of the liver. All had the typical history and physical findings of advanced portal cirrhosis, and were in a decompensated state with ascites. Blood histamine alone was determined in two patients in the terminal stages of cirrhosis, both being in deep coma at the time.

The effect of cortisone was studied in two of the patients who had high levels of histamine in the blood. After a control period of two days, $50 \mathrm{mg}$. of cortisone were given every 6 hours for three days, during which daily determinations of histamine were made on the blood and urine. Throughout the investigation, the patients were 


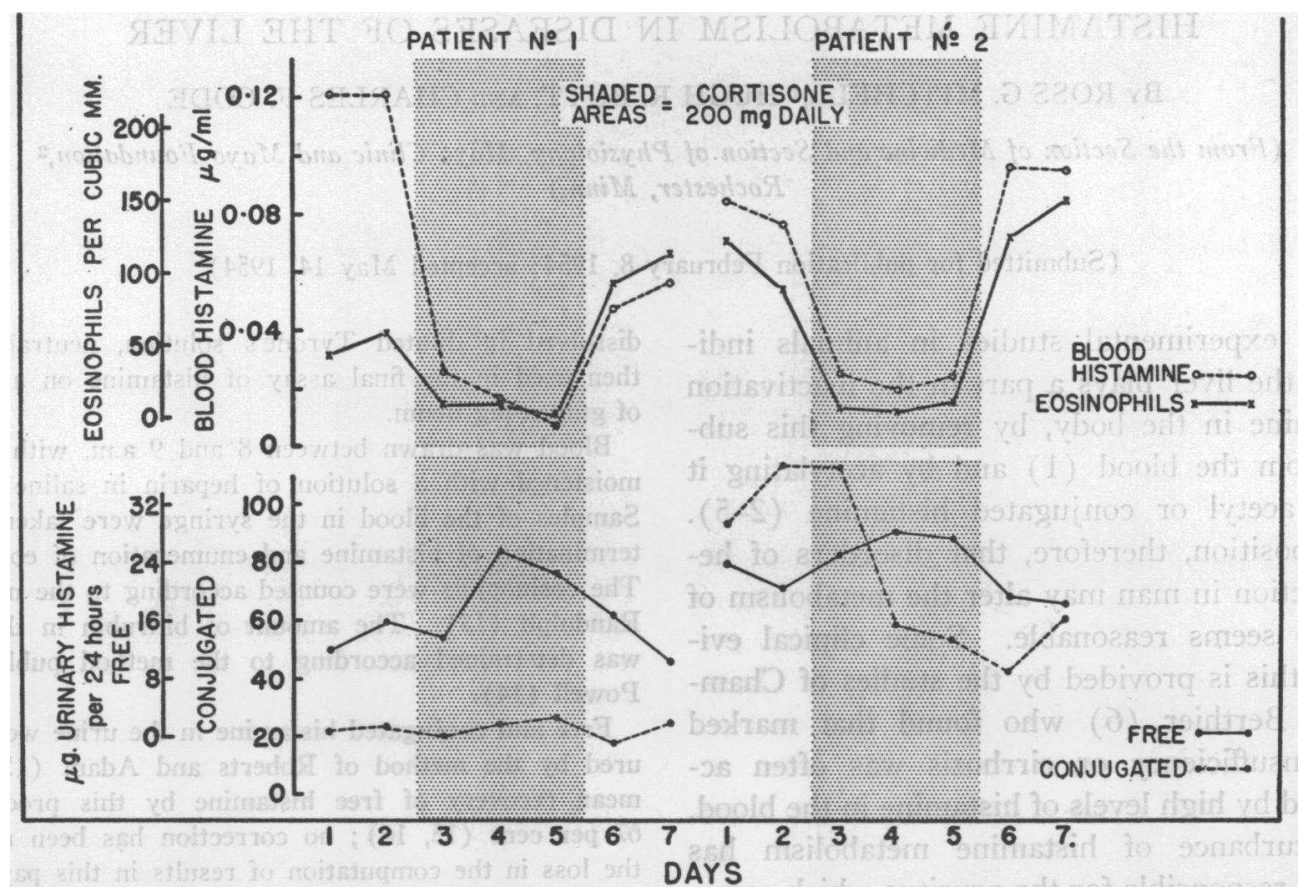

Fig. 1. Effect of Cortisone on Blood and Urinary Concentrations of Histamine in Two Patients with Cirrhosis of the Liver

on standard diets which provided almost exactly $100 \mathrm{Gm}$. of protein per day.

A study was made of 17 patients with proved obstructive jaundice. In most cases the obstruction was due to stricture of the bile passages or to malignant disease. Nine of the patients had a recent history of pruritus but complained of little or no itching when the blood was drawn, and they were placed in a group designated as having mild pruritus. Eight of the patients had moderate to severe pruritus when the blood was taken and they were placed in a group designated as having severe pruritus. In each case, urine was collected during the 24 hours preceding the venipuncture. There was no apparent clinical difference between the two groups, apart

TABLE I

Histamine content of the blood and urine of seven patients with cirrhosis of the liver

\begin{tabular}{|c|c|c|c|}
\hline \multirow[b]{2}{*}{ Patient } & \multirow{2}{*}{$\begin{array}{c}\text { Blood } \\
\text { histamine } \\
\text { Mg. per ml. }\end{array}$} & \multicolumn{2}{|c|}{$\begin{array}{l}\text { Urinary histamine } \\
\text { M\&. per } 24 \text { hours }\end{array}$} \\
\hline & & Free & Conjugated \\
\hline $\begin{array}{l}1 \\
2 \\
3 \\
4 \\
5 \\
6 \\
7\end{array}$ & $\begin{array}{l}0.121 \\
0.081 \\
0.037 \\
0.067 \\
0.051 \\
0.040 \\
0.075\end{array}$ & $\begin{array}{r}13.9 \\
20.9 \\
19.0 \\
20.5 \\
8.5 \\
9.5 \\
11.8\end{array}$ & $\begin{array}{r}28 \\
104 \\
100 \\
147 \\
227 \\
54 \\
109\end{array}$ \\
\hline Mean & 0.067 & 14.9 & 110 \\
\hline
\end{tabular}

from the degree of itching, nor did they differ significantly in the depth of jaundice or in standard measurements of hepatic function.

In one patient with severe pruritus, an assessment was made of the effects of cortisone and of methyl testosterone on the levels of blood and urinary histamine and on the degree of itching.

In order to obtain an estimate, by the methods we used, of the concentration of histamine in the blood of a comparable group of persons in good health, the level of histamine in the blood was determined on at least two different occasions in a group of 12 normal adults.

\section{RESULTS}

Normal persons. The mean concentration of histamine in the blood of the 12 healthy adults was $0.040 \mu \mathrm{g}$. per milliliter with a standard deviation of 0.011 and a standard error of \pm 0.002 . The maximal and minimal concentrations encountered in the series were 0.067 and $0.012 \mu \mathrm{g}$. per milliliter, respectively.

Patients with cirrhosis. The mean concentration of histamine in the blood of the seven patients with cirrhosis (Table I) was $0.067 \mu \mathrm{g}$. per milliliter \pm 0.011 and this is significantly higher than the mean for the 12 healthy adults $(p<0.001)$. 
The values in the patients ranged from 0.037 to $0.121 \mu \mathrm{g}$. per milliliter. In contrast, the two patients in the terminal stages of hepatic coma had very low levels of histamine in the blood, 0.017 and $0.010 \mu \mathrm{g}$. per milliliter, respectively.

The mean daily excretion of free histamine in the urine of the patients with cirrhosis was $14.9 \pm$ $2.3 \mu \mathrm{g}$. per 24 hours, with a range from 8.5 to $20.9 \mu \mathrm{g}$. This mean does not differ significantly from that found in another study for normal men $(17.7 \pm 1.2 \mu \mathrm{g}$. per 24 hours) and the range falls within the normal range of 8.0 to $26.9 \mu \mathrm{g}$. per 24 hours. The values for conjugated histamine were also within the normal range (Table I).

The administration of cortisone to two of the patients with cirrhosis was accompanied by a decisive fall in the concentration of blood histamine and by a rise in the 24-hour output of free histamine in the urine (Figure 1).

Patients with jaundice. The mean concentration of histamine in the blood of the patients with mild pruritus was $0.052 \pm 0.007 \mu \mathrm{g}$. per milliliter (Table II) and the mean of the group with severe pruritus was $0.078 \pm 0.009 \mu \mathrm{g}$. (Table III). The difference between these means is just significant $(p<0.05)$ and both are significantly higher than the mean normal value $(p<0.02$ and $<0.001$, respectively). Only two of the nine values in the group with mild pruritus fell outside the normal range but five of the eight in the group with severe pruritus were at or above the upper limit of the values obtained in the normal group of people (0.067 $\mu$ g. per milliliter).

The mean values for excretion of free histamine in the urine were $13.5 \pm 2.6$ and $15.7 \pm 3.7 \mu \mathrm{g}$. per 24 hours for the mild and severe groups, respectively. These do not differ significantly from one another nor from the mean values for excretion in normal adults.

When cortisone was given to the patient with severe itching, the concentration of blood histamine fell from 0.067 to $0.025 \mu \mathrm{g}$. per milliliter, but the itching persisted. The administration of 20 $\mathrm{mg}$. of methyl testosterone per day, resulted in almost complete relief of itching; daily determinations of blood and urinary histamine during the first three days of treatment showed no significant alteration from the pretreatment levels.
TABLE II

Histamine content of the blood and urine of nine patients with obstructive jaundice and mild pruritus

\begin{tabular}{|c|c|c|c|c|c|}
\hline \multirow[b]{2}{*}{ Patient } & \multicolumn{2}{|c|}{$\begin{array}{l}\text { Serum bilirubin } \\
\text { mg. per } 100 \mathrm{ml} .\end{array}$} & \multicolumn{2}{|c|}{$\begin{array}{l}\text { Urinary histamine } \\
\text { Mg. per } 24 \text { hours }\end{array}$} & \multirow{2}{*}{$\begin{array}{c}\text { Blood } \\
\text { histamine } \\
\text { Mg. per ml. }\end{array}$} \\
\hline & Direct & $\begin{array}{l}\text { Indi- } \\
\text { rect }\end{array}$ & Free & $\begin{array}{l}\text { Conju- } \\
\text { gated }\end{array}$ & \\
\hline $\begin{array}{l}1 \\
2 \\
3 \\
4 \\
5 \\
6 \\
7 \\
8 \\
9\end{array}$ & $\begin{array}{r}3.7 \\
14.0 \\
6.1 \\
11.6 \\
10.1 \\
5.5 \\
6.6 \\
5.2 \\
13.6\end{array}$ & $\begin{array}{l}1.5 \\
4.7 \\
2.1 \\
3.6 \\
2.8 \\
1.5 \\
1.6 \\
1.8 \\
3.5\end{array}$ & $\begin{array}{r}25.5 \\
23.6 \\
6.1 \\
9.1 \\
6.4 \\
10.4 \\
8.5 \\
10.5 \\
21.2\end{array}$ & $\begin{array}{r}44 \\
169 \\
23 \\
149 \\
54 \\
24 \\
19 \\
26 \\
35\end{array}$ & $\begin{array}{l}0.050 \\
0.044 \\
0.030 \\
0.045 \\
0.054 \\
0.042 \\
0.032 \\
0.100 \\
0.068\end{array}$ \\
\hline Mean & 8.5 & 2.6 & 13.5 & 59 & 0.052 \\
\hline
\end{tabular}

\section{COMMENT}

The mean concentration of $0.04 \mu \mathrm{g}$. of histamine per milliliter of blood of the 12 normal persons we studied was identical with the mean concentration observed in the blood of 103 medical students by Haworth and Macdonald (17) and identical with the mean concentrations found in the blood of 50 normal persons by Rose and Browne (18) and 20 normal adults by Randolph and Rackemann (19). The values obtained in these series ranged from 0.01 to $0.08 \mu \mathrm{g}$. of histamine per milliliter of blood which only slightly exceed the limits noted in our group. Apparently when identical technics are used the concentration of histamine found in the blood of normal persons in the British Isles, Canada, and the United States falls within rather narrow limits. The only sizable series of determinations in which values for normal persons beyond these limits have been obtained is that re-

TABLE III

Histamine content of the blood and urine of eight patients with obstructive jaundice and severe pruritus

\begin{tabular}{|c|c|c|c|c|c|}
\hline \multirow[b]{2}{*}{ Patient } & \multicolumn{2}{|c|}{$\begin{array}{l}\text { Serum bilirubin } \\
\text { mg. per } 100 \mathrm{ml} .\end{array}$} & \multicolumn{2}{|c|}{$\begin{array}{l}\text { Urinary histamine } \\
\text { Mg. per } 24 \text { hours }\end{array}$} & \multirow{2}{*}{$\underset{\text { histamine }}{\text { Mlood }}$} \\
\hline & Direct & $\begin{array}{c}\text { Indi- } \\
\text { rect }\end{array}$ & Free & $\begin{array}{l}\text { Conju- } \\
\text { gated }\end{array}$ & \\
\hline $\begin{array}{l}1 \\
2 \\
3 \\
4 \\
5 \\
6 \\
7 \\
8\end{array}$ & $\begin{array}{r}12.9 \\
1.2 \\
6.6 \\
2.0 \\
13.6 \\
11.9 \\
18.0 \\
17.0\end{array}$ & $\begin{array}{l}3.1 \\
0.3 \\
3.4 \\
0.8 \\
4.2 \\
2.5 \\
4.0 \\
3.7\end{array}$ & $\begin{array}{r}39.1 \\
7.2 \\
17.6 \\
14.8 \\
17.5 \\
7.9 \\
14.7 \\
6.9\end{array}$ & $\begin{array}{r}140 \\
20 \\
56 \\
74 \\
6 \\
18 \\
15 \\
153\end{array}$ & $\begin{array}{l}0.130 \\
0.100 \\
0.057 \\
0.053 \\
0.061 \\
0.083 \\
0.071 \\
0.067\end{array}$ \\
\hline Mean & 10.4 & 2.7 & 15.7 & 60 & 0.078 \\
\hline
\end{tabular}


ported by Valentine, Pearce, and Lawrence (20) who obtained a mean value of $0.075 \mu \mathrm{g}$. per milliliter with a range of 0.03 to 0.11 in the blood of 17 fasted normal subjects. The upward shift of the mean and of the extreme values suggests some difference in the technics employed.

The decisive decline in the concentration of histamine in the blood and the rise in the output of free histamine in the urine which accompanied the administration of cortisone to the patients with cirrhosis were similar to, though possibly more pronounced than, the changes produced by the hormone in healthy persons (16). This response may reflect a fundamental shift in histamine metabolism which the hormone produces, since it has now been uniformly observed in normal persons, patients with allergic disease and patients with cirrhosis of the liver.

In cirrhosis of the liver and in obstructive jaundice, the mean levels of histamine in the blood were significantly higher than normal. These results confirm those of Chambon and Berthier (6), although the very high values recorded by these authors (up to $0.30 \mu \mathrm{g}$. per milliliter) were not obtained.

The finding of an increase in blood histamine accompanied by a normal value for excretion of histamine in the urine of these patients suggests that the high blood levels were not due to liberation of histamine into the plasma, since in such circumstances increased urinary excretion would be expected (21). It is possible, of course, that histamine was retained in the plasma because the kidneys failed to excrete it, but it appears more likely that the high values were due to a disturbance of hepatic function resulting in an increase in histamine in other elements of the blood, possibly in the eosinophilic or basophilic leukocytes. The high values may in some fashion have represented a compensatory mechanism related to the failing liver for when complete dissolution of hepatic function occurred, as was the case in the comatosed patients, the increased quantities of histamine disappeared from the blood.

The results of the study of patients with jaundice and pruritus indicate that there is a relationship between the degree of pruritus and the level of histamine in the blood, in that the more severe the itching the higher the level of blood histamine is likely to be. In cirrhosis, however, high values for blood histamine were found in the absence of itching. Even in the patients with jaundice, the high values for blood histamine did not appear to be the direct cause of the pruritus, since no relief was obtained when the level was lowered by means of cortisone. The elevated blood values simply indicate that the metabolism of histamine is altered when the liver is damaged by cirrhosis or biliary obstruction, and the occurrence of pruritus in the patients with obstruction is apparently related to this altered metabolism.

The relief of itching by the use of methyl testosterone was reported by Lloyd-Thomas and Sherlock in 1952 (22), who commented that the rationale of its use was not known. The lack of effect on the levels of blood and urinary histamine in our patient treated with this hormone suggests that it did not produce the observed relief by correcting the altered metabolism of histamine but rather by some other mechanism.

\section{SUMMARY}

The mean concentration of histamine in the blood of patients with cirrhosis and of patients with jaundice caused by biliary obstruction was significantly higher than the concentration in the blood of a group of healthy persons. In the series of patients with jaundice, there was a relationship between the degree of pruritus and the level of histamine in the blood, the more severe the itching the higher the concentration of blood histamine was likely to be.

The values for free and conjugated histamine excreted daily in the urine of the patients with cirrhosis and of those with jaundice were within the limits found in normal persons.

When cortisone was given to two of the patients with cirrhosis, the concentration of histamine in the blood fell decisively and the output of free histamine in the urine increased.

The administration of cortisone to one of the patients who had jaundice with severe pruritus resulted in prompt decline of the concentration of blood histamine without relief of the itching, while administration of methyl testosterone to the same patient resulted in prompt relief of the itching without change in the level of histamine in the blood. 


\section{REFERENCES}

1. Anrep, G. V., Barsoum, G. S., and Talaat, M., Release of histamine by the liver. J. Physiol., 1953, $120,419$.

2. Urbach, K. F., Nature and probable origin of conjugated histamine excreted after ingestion of histamine. Proc. Soc. Exper. Biol. \& Med., 1949, 70, 146.

3. Tabor, H., and Mosettig, E., Isolation of acetyl-histamine from urine following oral administration of histamine. J. Biol. Chem., 1949, 180, 703.

4. Trethewie, E. R., and Gaffney, F. M., The presence of "bound" histamine following the injection of histamine acid-phosphate into the perfused liver. Australian J. Exper. Biol. \& Med., 1951, 29, 67.

5. Millican, R. C., The acetylation of histamine in normal and enterectomized rats. Arch. Biochem., $1953,42,399$.

6. Chambon, M., and Berthier, J., Histamine et histaminasémie au cours des lésions hépatiques. Compt. rend. Soc. de biol., 1945, 139, 506.

7. Rosenthal, F., Uber das Wesen und die Behandlung des Hautjuckens beim Ikterus. Therap. d. Gegenw., 1929, 70, 297.

8. Schachter, M., Release of histamine from skin by neoarsphenamine and bile salt. J. Physiol., 1952, 116, $10 \mathrm{P}$.

9. Anrep, G. V., and Barsoum, G. S., Blood histamine in experimental obstruction of the common bile duct. J. Physiol., 1953, 120, 427.

10. Code, C. F., The quantitative estimation of histamine in the blood. J. Physiol., 1937, 89, 257.

11. Barsoum, G. S., and Gaddum, J. H., The pharmacological estimation of adenosine and histamine in blood. J. Physiol., 1935, 85, 1.
12. Code, C. F., Hallenbeck, G. A., and Gregory, R. A., Histamine content of canine gastric juice. Am. J. Physiol., 1947, 151, 593.

13. Randolph, T. G., Blood studies in allergy. I. The direct counting chamber determination of eosinophils by propylene glycol aqueous stains. J. Allergy, 1944, 15, 89.

14. Powell, W. N., A method for the quantitative determination of serum bilirubin with the photoelectric colorimeter. Am. J. Clin. Path., 1944, 14 (Technical Section 8), 55.

15. Roberts, M., and Adam, H. M., New methods for the quantitative estimation of free and conjugated histamine in body fluids. Brit. J. Pharmacol., 1950, $5,526$.

16. Mitchell, R. G., and Code, C. F., Unpublished data.

17. Haworth, E., and Macdonald, A. D., On histamine in cotton dust, and in the blood of cotton workers. J. Hygiene, 1937, 37, 234.

18. Rose, B., and Browne, J. S. L., Alterations in the blood histamine in shock. Proc. Soc. Exper. Biol. \& Med., 1940, 44, 182.

19. Randolph, T. G., and Rackemann, F. M., The blood histamine level in asthma and in eosinophilia. J. Allergy, 1941, 12, 450.

20. Valentine, W. N., Pearce, M. L., and Lawrence, J. S., Studies on the histamine content of blood, with special reference to leukemia, leukemoid reactions and leukocytoses. Blood, 1950, 5, 623.

21. Adam, H. M., Excretion of histamine in human urine. Quart. J. Exper. Physiol., 1950, 35, 281.

22. Lloyd-Thomas, H. G. L., and Sherlock, S., Testosterone therapy for the pruritus of obstructive jaundice. Brit. M. J., 1952, 2, 1289. 